\title{
Zum hundertsten Geburtstag von Fielding H. Garrison
}

\author{
Von Erwin H. Ackerknecht
}

Am 5. November 1970 jährt sich die Geburt von Fielding Hudson Garrison zum hundersten Mal. Es ist eine elementare Pflicht der Dankbarkeit bei dieser Gelegenheit des Mannes zu gedenken, dessen Introduction und Texts illustrating (kurz der Garrison-Morton genannt) das unentbehrliche und handlichste Handwerkszeug für jeden, der sich mit Medizingeschichte beschäftigt, darstellen. Dazu haben weit über das Belehrende hinaus, sich durch seine Werke die Begeisterung des Verfassers für die Geschichte, für alles Gute, Schöne und Fortschrittliche seinen zahlreichen Lesern mitgeteilt.

Garrison kam 1870 in der Bundeshauptstadt Washington als Sohn eines Beamten aus dem Südstaat Virginia auf die Welt. Er war einer der ersten, die an der jungen Johns-Hopkins-Universität einen Bachelor of Arts erwarben (1890). Dabei fiel er John Shaw Billings auf, dem Gründer und Direktor der Surgeon Generals Library (jetzt National Library of Medicine), der auch an Johns Hopkins unterrichtete. 1891 trat er in den Dienst der Bibliothek. Nebenbei studierte er noch Medizin. Seine eigentliche Liebe hatten der Mathematik und Musik gehört. Aber die ökonomische Lage seines Vaters bedingte diese Laufbahn eines medizinisch gebildeten Bibliothekars, zu der auch noch eine militärische Karriere gehörte die Bibliothek gehörte ja damals der US Army. In letzterer Funktion wurde er schließlich Oberst und mußte die Jahre 1920-1922 in Manila verbringen. Sonst blieb er bis zu seiner Pensionierung 1930 an der Washingtoner Bibliothek. Dann wurde er Direktor der soeben von William $\mathrm{H}$. Welch gegründeten und nach ihm benannten Bibliothek der Johns Hopkins Medical School in Baltimore und Lektor für Medizingeschichte in dem erst von Welch, dann von H. E. Sigerist geleiteten Institut. Diesem Wirken setzte aber bereits am 18.4.1935 ein Darmkrebs ein Ende.

Unter dem Einfluß von John Shaw Billings, dessen Biographie er auch schrieb, hat sich Garrison vor allem an den unvergleichlichen bibliographischen Werken der Washingtoner Riesenbibliothek: dem Index Catalogue und dem Index Medicus betätigt. Ein Nebenprodukt dieser ebenso nützlichen wie unspektakulären Tätigkeit, die 1912 erschienenen Texts illustrating the history of medicine, ist von dem englischen Bibliothekar Morton weitergeführt, als « Garrison-Morton» noch heute viel benützt.

Garrisons Meisterwerk wurde aber die 1913 zum erstenmal erschienene einbändige Introduction to the History of Medicine, die an Reichhaltigkeit, Gründlichkeit und Brillianz bis heute nicht ihresgleichen gefunden hat. Natürlich war, wie 
oft betont, die Verbindung mit der größten medizinischen Bibliothek der Welt eine der Grundvoraussetzungen für dieses erstaunliche Buch. Aber geschrieben hat es nicht die Bibliothek, sondern der Autor, dem diese Bibliothek sogar nur wenig Zeit für sein Werk ließ. Über der Introduction sollten nicht die mehr als 200 kleineren Arbeiten vergessen werden, insbesondere die Monographien zur Geschichte der anatomischen Illustration, der Militärmedizin, der Pädiatrie, Neurologie und Endokrinologie. Auch die von Hafner, New York, in dankenswerter Weise 1966 herausgebrachte Sammlung von kürzeren Artikeln Garrisons enthält sehr viel Wertvolles.

Neben dieser gigantischen Arbeitsleistung half der überraschend bescheidene Forscher noch allen Adepten der Medizingeschichte bei der Materialbeschaffung aufs großzügigste. Gegen Ende seines Lebens häuften sich allerdings Konflikte des sehr empfindlichen Mannes mit seiner Umgebung. Man hat dies aus den Strapazen seines Philippinenaufenthaltes erklärt. Mir scheint, daß die Entwicklung sowieso unvermeidlich war. Garrison war in dem Milieu, in das er hineingeboren war, verurteilt, eine einsame, verbitterte, tragische Figur zu sein, die auch äußerer Erfolg nicht über seine Isolierung hinwegtrösten konnte. Wie sollte er, der Baseball und Politik verabscheute, wie sollte der Sprachkundige und in seiner Gelehrsamkeit (und seiner Unfähigkeit als Redner) an einen Littré Erinnernde, wie sollte der allen kulturellen Werten, besonders der Musik (sein Lieblingskomponist war der ebenfalls kurzgewachsene Brahms) Aufgeschlossene nicht einsam sein in einem Milieu, das solche Eigenschaften bestenfalls als skurril ansah? Wie sollte der eher musisch Veranlagte, den man in eine Uniform gesteckt und an zwei Bibliographien gekettet hatte, nicht verbittern?

Trotz all diesen Schwierigkeiten hat Garrison sich nicht in Selbstmitleid verloren, sondern seinem beschwerlichen Dasein reiche Frucht abgerungen. Er ist zweifellos der größte Medizinhistoriker gewesen, den die us A bisher hervorgebracht haben. Und der am wenigsten Provinzielle und der Umfassendste aller Länder und Zeiten, da die us A zu seiner Zeit noch keinen Prioritätskomplex entwickelt hatten. Er gehört zu jener internationalen «medizinhistorischen Welle», die kurz vor und nach dem Ersten Weltkrieg sich in Europa und Amerika erhob. In den US A war sie mehr bibliophil-bibliographisch gefärbt (Osler-Billings), während sie in Europa mehr philologisch-philosophisch (Sudhoff-Neuburger) orientiert war.

Garrison wird heute zuweilen als «altmodisch» bezeichnet. Im Grunde bedeutet dieser Tadel, wenn er von denen kommt, die auch in unserer Wissenschaft Unwissenheit und Gedankenarmut mit metaphysischem und «sozialwissenschaftlichem » Geschwätz maskieren wollen, hohes Lob. Garrison basierte in der Tat in altmodischer Art seine historischen Gedanken auf enormen Kenntnissen der Medizin der Vergangenheit und seiner Gegenwart; und er schrieb in einer klaren, schönen, unprätentiösen Sprache. Darum wird sein Werk auch noch lang über unsern Dank hinaus weiterleben. 


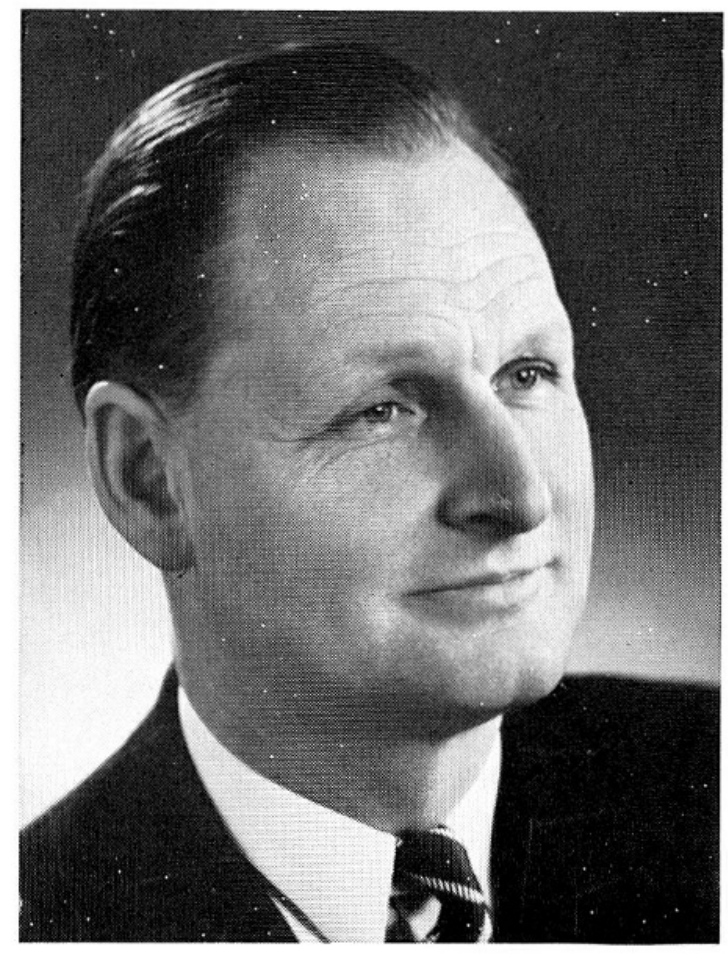

Dr. phil. Eduard Fueter 